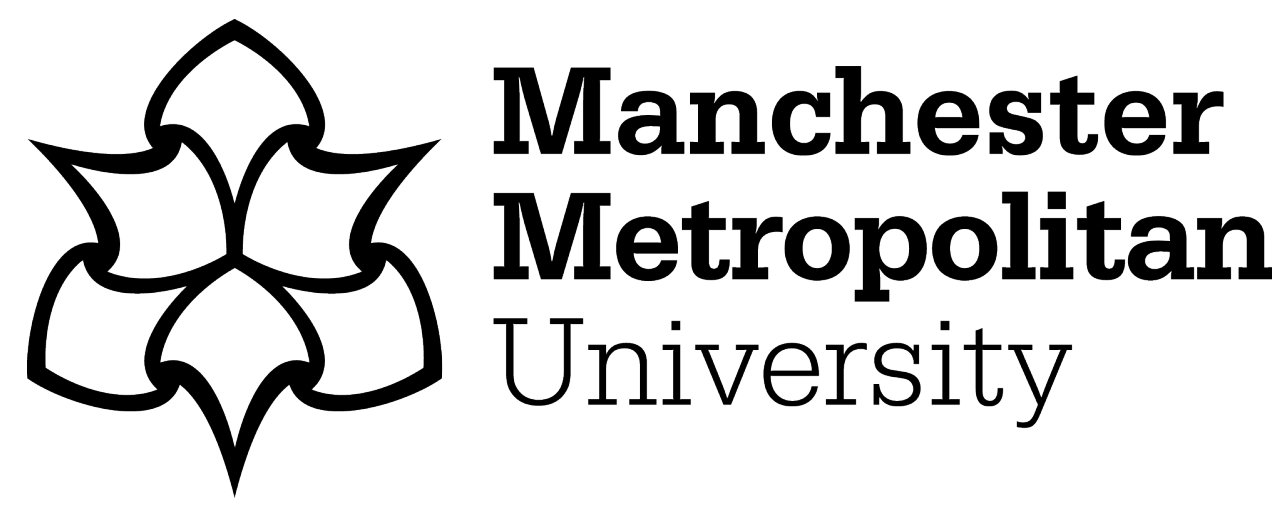

Hart, D (2019) A systemic 'Theories of Change' approach for projects and change initiatives in the context of quality enhancement activity in Higher Education. In: Problem Structuring Approaches for the Management of Projects: Demonstrating Successful Practice. Springer, pp. 1-34. ISBN 978-3-319-93263-7

Downloaded from: https://e-space.mmu.ac.uk/620412/

Version: Accepted Version

Publisher: Springer

DOI: https://doi.org/10.1007/978-3-319-93263-7

Please cite the published version 


\title{
A systemic 'Theories of Change' approach for projects and change initiatives in the context of quality enhancement activity in Higher Education
}

Dr Diane Hart

Manchester Metropolitan University

Pre-print manuscript- Accepted 19/4/18 -For publication in Bell,G., Pagano, R., Sato, C., and Warwick, J. (Eds) Problem Structuring Approaches for the Management of Projects: Demonstrating Successful Practice, Basingstoke:Palgrave Macmillan Ltd.

\begin{abstract}
A systemic Theory of Change approach to projects and change initiatives is explained and illustrated in the context of educational development activity using case studies from a large UK University. The approach involves facilitated modelling used to support organisational learning. Models are updated through action learning cycles of planning, implementation, evaluation and reflection. The theoretical basis is justified in relation to reflective practice, organisational learning, participative and theorybased programme evaluation and critical systems thinking. The critical reflection from its application to the case studies is not presented as 'proof' of effectiveness or good practice, but only to provide insight into what was found useful and learned from the applications in this context, to help others assess the usefulness and transferability to their situations of interest.
\end{abstract}

Keywords: Theory of Change; Facilitated modelling; Programme Evaluation; Systems thinking; Organisational learning.

\section{Introduction}

Theories of Change (ToC) is an evaluation approach emerging in the context of community change initiatives in the US (Connell and Kubisch 1998). It has since been used more widely in other countries and sectors, e.g. health (Sullivan et al. 2002, Barnes et al. 2003, Mackenzie and Blamey 2005, Sullivan and Stewart 2006, Breuer et al. 2016), education and higher education (Hart et al. 2009a, 2009b, Levy 2012, Richards et al. 2016), community development (Archibald et al. 2016), crime (Hopkins and Wickson 2013) and agriculture (Mayne and Johnson 2015, Thornton et al. 2017). Although ToC has evolved in the discipline of evaluation theory and practice, it is not restricted to this purpose. The approach involves facilitated development of models that can form the basis for planning implementation and evaluation activity, and reflecting on the results of evaluation, to inform decisions about further improvement. Those familiar with soft OR and problem structuring methods will recognise elements of the approach. However, it is anticipated that it will be new to practitioners more familiar with project management methodologies. 
The examples used in this chapter to illustrate the application of ToC are from educational development activity in the context of a large UK university. The term educational development is used to mean "systematic and scholarly support for improving both educational process and practices and capabilities of educators" (Stefani 2003, p.10). UK Universities are expected to undertake a process of systematic continuous improvement of their educational provision (Higher Education and Research Act 2017) guided by a quality code (Quality Assurance Agency 2017). However there continues to be debate about methods and measures to inform improvement efforts (Gibbs 2010). There has been much criticism of these efforts focusing on a narrow range of sector-wide quality assurance measures (Harvey and Williams 2010a, 2010b,).

The approach illustrated here is intended to help practitioners understand how their change strategies are working in the specific contexts of application. However it is adapted with some systems thinking to improve connection with the wider environment and higher level strategies. Systems thinking involves exploring a situation of interest 'as if it were' a complex adaptive system. The theoretical basis for this is explored in the next section. This is followed by a description of ToC applications in educational development projects, and finally a personal critical reflection on the learning from these applications.

\section{Theoretical background}

The theoretical model of organisational learning typically relied on to underpin quality enhancement processes in higher education is that of the reflective practitioner (Schön 1983, Kolb 1984). From this perspective, improvement action is assumed to be informed by practitioners actively engaged in attempting to understand how and why their implemented teaching strategies work (or not) in specific contexts of implementation. It is argued that through their everyday activity practitioners develop mental models about the complex dynamics of the situations in which they practise. These models have been termed 'theories of change' (or variations on this), and in reflective practice these theories are consciously and continuously tested and revised through learning cycles of planning, action, evaluation and reflection. More recently it has been argued that there is a need to develop improved and explicit theories of change (Trowler et al. 2014) with joined up thinking about the connection between change at different levels of organisation (Trowler et al. 2005, 2014). This organisation-wide learning and change requires this process to be undertaken collectively (Biggs 2001, Vince 2002) and through rigorous action research (Argyris and Schön 1996, Kember 2002, Marks-Maran 2015). However, a more formal and collective approach to educational action research has been acknowledged to present significant challenges in terms of the complexity of the social and political processes (Trowler et al. 2005). For example in motivating and engaging participants (Greenbank 2007), establishing shared goals and vocabulary for collaborative work (Jacobs 2016), and producing outputs that are more widely transferable and usable (Saunders 2012). 
Programme evaluation aims to improve theories of change about how intervention programmes work in practice in specific contexts and is used to inform decisions and actions to improve these situations (Funnell and Rogers 2011, Patton 2012). Typically this type of approach involves some sort of 'modelling' or 'problem structuring' of the situation of interest, which helps in framing the planning of data generation, analysis and interpretation. The approach is not prescribed, and there is much debate about how decisions about the evaluation design affect what is learnt and how evaluation is used to influence improvement. In addition to decisions about e.g. methods, data, participants, there are core decisions about whose theories are tested, and whose questions are answered. These choices can reflect fundamentally different assumptions about the complexity of improving organised activity and learning about how this can be achieved. For example the reflective practitioner or action research mode of inquiry described earlier is often considered to lack rigour because the investigator is too closely involved in the situation, and has a vested an interest in the findings and outcomes, which may bias their interpretation of them. The use of external 'experts' is often used to introduce this rigour. In the OR literature, Franco and Montibeller (2010) identify this expert mode as the most common and traditional approach to OR intervention. In this mode the assumption is that an [external] 'expert' can straightforwardly define 'success' and use objective and scientific methods of inquiry to measure success, discover how activity and other factors are influencing success, and therefore recommend solutions. However, the risk associated with this mode is that the prioritisation of the expert's definition and criteria of success will lead to findings not thought to be relevant or useful by other stakeholders, and will not be used (Patton 1986). This approach therefore does not appear compatible with enhancement processes, where improvement needs to be understood from the perspective of a wide range of stakeholders and is dependent on the actions of many actors. From a utilizationfocussed perspective (Patton 1986), the inquiry should help decision makers and others that have the ability to influence change in a situation to arrive at their own judgements about, and commitment to, the improvement needed. This suggests a more facilitated and developmental approach is needed. In the facilitated mode of OR intervention (Franco and Montibeller 2010), consultants facilitate a participative process of problem structuring with stakeholders to guide their intervention and inquiry. It is accepted that different stakeholders and actors involved will have different notions of success and how to achieve it, based on their previous experiences, learning, values, motivations, and the information to which they have access. Cause-effect relationships in these situations are therefore understood more as producer-product relationships that are socially constructed, i.e. through people's actions based on their own mental models of their effects in the complex contexts in which they act. Models are probabilistic rather than predictive, and the more complex the situation, the more uncertain the outcomes. In developmental approaches (Fetterman 1994, Patton 1994), the facilitator also helps in capacity building for organisational learning within the intervention context. 
In the ToC approach (Connell and Kubisch 1998), the starting point is that the facilitator engages stakeholders in articulating a 'plausible, doable and testable' model representing the desired change. There is no prescribed format for this model, other than it needs to capture sufficient relevant detail to communicate the key dimensions of the change process. What counts as sufficient and relevant is something for the participants to critically reflect on in the specific inquiry context. It can be used in the planning stages, to develop clarity and refinement of plans and communicate about these prior to and during implementation. The premise is that stakeholders will have a better understanding of, and commitment to, the change and their role in it, they are more likely to work collaboratively, and more likely to consider an intervention successful if it goes according to plan to achieve the desired changes. The approach also fits with the concept of developmental evaluation, with the potential to build capacity for organisational learning.

The benefits experienced by users of ToC have been variously reported. At the project level it has been found a useful framework for developing and documenting the evaluation strategy and different participants' perspectives, and to guide inquiry to focus on relevant questions, data collection and analysis, and to make sense of data collected (Mason and Barnes 2007). A review of ToC in the charity sector (James 2011) found that there were different approaches to implementing ToC in practice, which broadly fell into two categories. In the first category the focus was more on change that the project or programme brings. The second category involved approaches that were more exploratory in attempting to understand the process of change for a particular situation of interest, as well as the role of programme or project in enabling this. In particular, the following were found helpful:-

- consideration of the project or programme's connection with the wider organization/context of change.

- $\quad$ use of wider relevant learning from outside the project/programme (research and practice).

- $\quad$ involvement of diverse stakeholders taking ownership of the process.

- consideration of how key actors are influencing processes.

- $\quad$ simple models prioritising what is relevant.

- $\quad$ ongoing reflection and learning, rather than one-off workshops.

This may require facilitation by those with knowledge and skills associated more with those required for change management. This may be particularly challenging for project managers, as "except in projects where there is very little behavioral change required, the Project/Program Manager will not have the time or bandwidth to carry out all the change management activities required to ensure a successful outcome" (Crawford and Namheis, p.409). This chapter therefore attempts to provide some insight into the practical implementation of the approach. 
The challenges of $\mathrm{ToC}$ in practice were found to be (i) developing a process of ongoing reflection, and (ii) getting an appropriate balance in the model so that it was neither overly simple nor complex from the perspective of stakeholders (James 2011). Facilitators also found it helpful to avoid jargon, particularly "the term 'theory of change' - especially in the early stages of discussion - framing the process as one of reflection and learning" (James 2011, p.30). Other issues are the importance of flexibility in adapting its use to be appropriate to the scale and complexity of change (Davies 2004), and usability so it is not overly burdensome for stakeholders (Thornton et al. 2017). Associated project management processes also need to be more flexible (Archibald et al. 2016). The need for improving the ability to connect change between different levels has been highlighted (Archibald et al. 2016). As with all participative approaches, there needs to be trust between stakeholders (Archibald et al. 2016). It has been suggested that in most complex situations the aspiration of a fully participative process cannot be realised as there will always be a power dynamic influencing this. Instead it may be better to recognise different 'types' of ownership and participation in the methodology that may be useful for different purposes and different situations (Sullivan and Stewart 2006).

There is criticism in the literature that participative and facilitated approaches more generally are problematic with respect to the assumption that participants can be straightforwardly identified and their perspectives included (Ulrich 1987, Pawson and Tilley 1997, Mason and Barnes 2007, Midgley 2000). Someone's perspective will always be privileged in decisions about the process of stakeholder identification, and when perspective-seeking should cease. In order for action to be taken there is an "inevitability of argument break-off" (Ulrich 1987, p.277). Modelling may also be problematic in new, uncertain and complex situations where participants have no experience on which to base their judgements (Patton 2012), and stakeholders may not always be willing or able to participate (Ulrich 1987).

\section{'Systemic' Theories of change}

In the academic literature there is some discussion about what distinguishes 'project' and 'programme' (Crawford and Nahmias 2010, Gareis 2010), with case studies finding that practitioners often use the terms interchangeably (Crawford and Nahmias 2010). In this chapter, use of the terms fits with the definition of programme as "a group of related projects and change management activities that together achieve beneficial change for an organisation" (APM 2017), and project as " $a$ unique, transient endeavour undertaken to achieve planned objectives" (APM 2017). Change is something that is managed by a project or programme, it is not the project or programme per se (Gareis 2010). In order to manage change, it is necessary to conceptually set a boundary between a 'change object' and its context, and to consider the relevant internal and external elements and their 
relationships and dimensions. This "creates the basis for designing the change and planning the required change management interventions" (Gareis 2010, p.320).

This process of making boundary judgements is one that can be recognised in systemic inquiry. Using a lens of complex adaptive system to explore a situation of interest, it can be considered as having various components interacting together to co-produce 'something' or effect some change that they could not achieve individually. Systems also have a relationship with a wider environment, which has an influence on the activity undertaken, and the activity and transformation effected in turn influences the conditions in the environment. In human activity, the interacting components are people whose behaviour is influenced by their subjective motivations and interpretations, in turn influenced by their history and context. Bringing together multiple stakeholders to undertake some 'organised' activity is assumed to be inherently complex because this subjectivity in perspective influences each actor's contribution to the activity. This makes it highly subject to contextual influences, and means that outcomes are uncertain. In systemic inquiry, subjective value judgements are made about the boundaries scoping who and what is relevant to include in a situation of interest, and how boundaries are nested and interact. The inquiry attempts to interpret how these different perspectives on boundaries influence the dynamics of a situation through a process of boundary critique.

Churchman (1971) suggested that for any organised human activity, the following concepts could be used to guide this process of boundary critique. The aim is to provide insight that can inform decisions about change.

Purpose: i.e. the change that the organised activity affects. In learning and teaching activity this might be some improvement in students' knowledge or skills, or ability to contribute to society in some way. The intended change might be explicitly stated (e.g. as intended learning outcomes in a module handbook). Any stakeholder (e.g. teachers, learners, parents, employers...) may have their own interpretations of this purpose, and participants will have their own motivations and expectations of what they want to get out of being involved. This may or may not be aligned with the stated purpose, but it will affect how they behave in the activity, or how they judge it to be successful.

Measures of performance: These reflect assumptions about progress or success in relation to the stated purpose. It is participants' interpretation of this that often guides their behaviour. One of the challenges faced in relation to learning and teaching enhancement is in actually defining what is meant by 'enhancement' (Kirkwood and Price 2014, Gunn and Fisk 2013) and the criteria used to measure this to be relevant to different stakeholders and different contexts (Gibbs 2010, Barefoot et al. 2016). 
Client: The purpose and performance is in relation to serving their interests. Theory about good teaching practice in organised learning activity is that it should be student-centred (Biggs and Tang 2011). However, this may not be the perception of all stakeholders.

Component activities: These work together, directed towards achieving the purpose. These are undertaken by actors each with their own perceptions and motivations with respect to their role and performance in this role.

Environment: This is the context of the organised activity. This influences interpretations of 'relevance' of purpose in terms of the relationship with the wider environment, and therefore the sustainability of the activity. As well as being affected by contextual conditions, the activity also contributes to creating these conditions. How this relationship is working in practice is a value judgement. There is a common assumption in the UK that higher education seeks to ensure a future workforce with appropriate knowledge and skills to meet the needs of UK employers so that the UK can compete in a global economy (UKCES 2014, DBIS 2016). The extent to which this is the case, or indeed relevant, for any organised learning activity is a value judgement from each stakeholder's perspective.

Decision maker: This role organises activity and allocates resources towards achieving the purpose. It communicates purpose and performance measures to participants. Roles and responsibilities may not be interpreted in the same way by all stakeholders. Similarly communications may not be interpreted or responded to in the way intended. In learning and teaching activity, students may come into contact with e.g. module leaders, contributing tutors, heads of department, administrators, other students. Communication about the purpose, organisation, assessment etc, may not be consistent from different sources. Students may also have different frames of reference influencing their interpretations, based on subjects previously studies, institutions previously attended, their home department and programme.

Designer: The designer's role is to advise the decision maker on the relevancy of the purpose of the organised activity to being sustainable in its environment, and on the different ways activity could be organised and its performance evaluated, and the potential implications of these decisions. This role supports the decision maker in making informed decisions about implementation and change. It therefore undertakes intelligence gathering and analysis. In practice the role of designer and decision maker can be undertaken by the same individual(s). In learning and teaching, an example might be the module leader. The identification of these as two separate roles rather than individuals also focuses inquiry into how this relationship is working in practice. In the example of learning and teaching enhancement projects, this raises questions about how the initial project designs are informed, how the implementation compares to the initial design, how this is evaluated and how useful the project leader finds this evaluation in informing their improvement plans. 
Stability: There is an assumption that the activity is stable enough for the designer to make sense of data and information about its state, and to experientially learn over time about the likely connections between activity and outcomes in particular contexts, thus reducing the uncertainty about the implications of future action. Changes in the wider environment can be destabilising. Saunders et al. (2005) argued that one of the benefits of modelling and evaluation is their use as 'bridging tools' during periods of instability. They can provide stakeholders with a common frame of reference, bringing some 'provisional stability' from which to make sense of experience, data and information, in order to plan change.

During the last 20 years there has been growing interest in how the fields of systems and evaluation are connected (Imam et al. 2007, Hummelbrunner 2011), and how systems thinking can inform evaluation practice (Gates 2017). It has been argued that systems thinking could help with some of the challenges identified with evaluating complex interventions, providing concepts to guide inquiry into how specific situations are constructed and understood by multiple stakeholders, and how multiple 'levels' of change are connected (Barnes et al. 2003, Virtanen and Uusikylä 2004), and to help critically reflect on the relationship between the evaluation and the intervention being evaluated (Midgely 2000). There has also been some exploration of the application of systems thinking to higher education quality processes, in particular concepts associated with complex adaptive systems (Davis and Sumara 2005, Radford 2006, 2008, Houston 2008a, b). However, there are limited case studies that actually illustrate and critically reflect applications in higher education (Hart and PaucarCaceres 2017).

It is outside the scope of this chapter to provide a more in-depth explanation of systems theory and critique its various interpretations in methodology and approaches. For this, interested readers can investigate some of the original source material (e.g. Ackoff 1981, Beer 1985, Churchman 1971, Checkland 1981, Jackson 2003, Midgley 2000). The following section illustrates application of systems thinking to $\mathrm{ToC}$ in educational development projects in a UK university, and provides a critical reflection on these cases.

\section{Application to case studies}

\section{Organisational context}

The case studies discussed in this chapter were all projects incentivised by institutional resource specifically earmarked for innovative learning and teaching enhancement projects. Individuals or teams of academic staff would bid for additional resources to help develop, implement and evaluate new ideas. Criteria for successful bids were based on the potential for projects to contribute to strategic priorities for enhancement and learning about good practice identified by government and the institution. Much of the resource provided was in the form of skills, expertise and labour provided by specialist professional staff employed by the University, e.g. educational developers and advisors. 
The ToC approach was introduced to address a number of problems perceived by university management to be linked to organisational learning about enhancement activity (see Hart et al. 2009a for further detail). The intention was to improve this activity by engaging staff in a more systematic and institutional approach to organisational learning about how innovation and change in teaching practice was influencing enhancement. These problems, and how to address them continue to be discussed within the wider higher education sector (e.g. Biggs 2001, Trowler et al. 2005,2014, Houston 2008a, Gibbs 2010, Bamber and Anderson 2012).

My role in this context was as an educational advisor supporting the evaluation of learning and teaching enhancement projects. Whilst there was an accountability dimension to project evaluation, the evidence the institution was seeking with respect to this was that the project teams were engaged in learning about their innovative practice and were sharing this learning more widely. Although decision making responsibility about the evaluation rested with project leaders, the expectation was that this would be facilitated by an advisor, leading to a more consistent quality and format of findings to help in the evaluation of the institutions wider learning and teaching strategy. However, using a participative ToC approach was assumed to be more likely to be viewed by project leaders as relevant to their own needs in terms of informing their own decisions about enhancement and wider dissemination of good practice, thus improving their engagement.

\section{Format of a Theory of Change model}

A model inherently is intended to 'represent' something rather than exactly replicate it. It is often simplified to dimensions most relevant its user's purpose(s). There is no prescribed format for a ToC model. One approach commonly used is to map assumed cause-effect pathways for a project or programme intervention, in terms of inputs, outputs and outcomes (logic models), and to specify indicators for the changes. Sometimes this is accompanied by a rationale for the model. A traditional and simple logic model for a learning and teaching project might look something like that in Figure 1.

\section{Figure 1: Simplified linear logic model for educational development project}

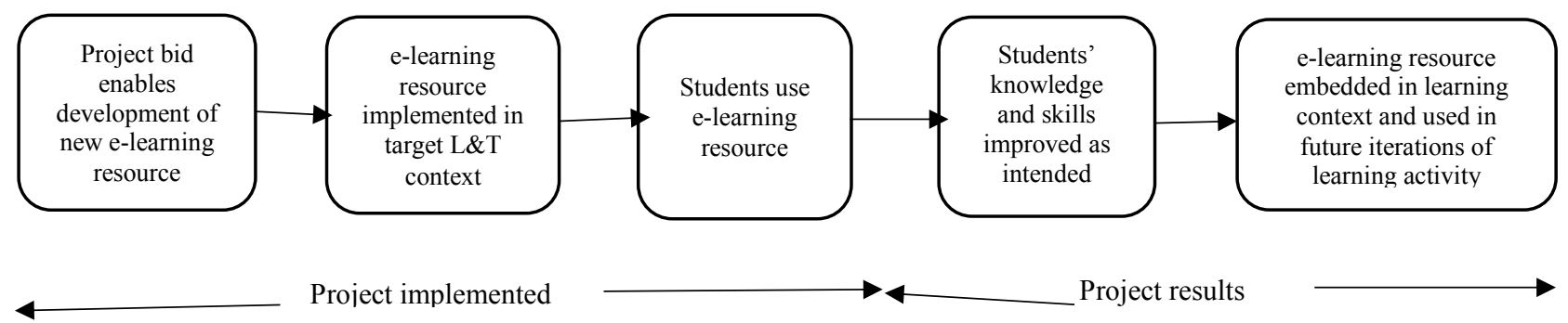

In $\mathrm{ToC}$ implementations in the charity sector, this linear and unidirectional approach to modelling and investigating change was found to be less helpful than more exploratory approaches (James 2011). However, the issue of keeping models simple and relevant to stakeholders was still important. To encourage more systemic thinking, Hummelbrunner (2011) suggests using a 'circular' logic model 
(Figure 2) whereby "every inter-relationship can be both-cause and effect-and does not only work one way" (Hummelbrunner 2011, p403), hence investigation seeks to identify interaction patterns.

Figure 2: 'Circular' Logic Model (Adapted from Hummelbrunner 2011, p403)

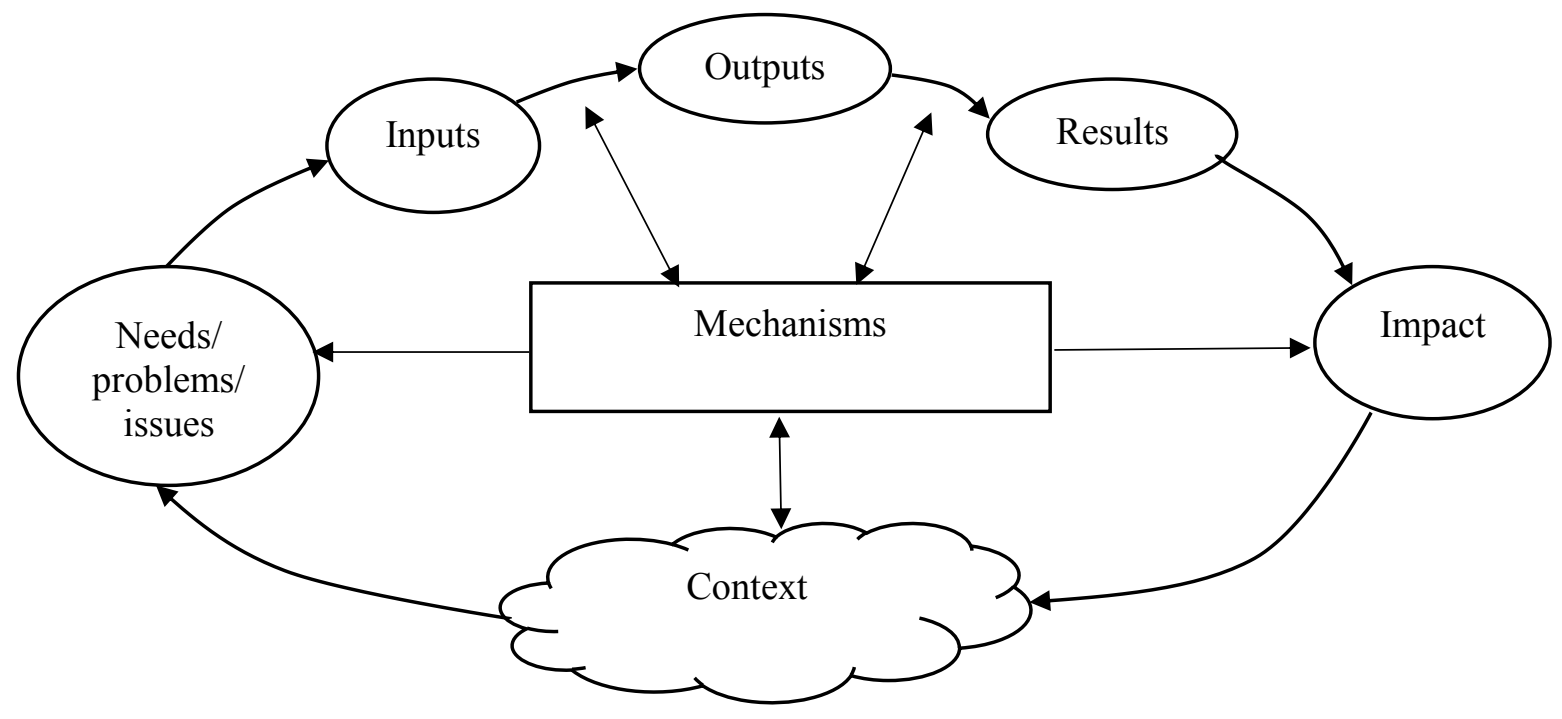

A challenge for those facilitating $\mathrm{ToC}$ in the educational development projects was to develop a model format that guided project leaders in a more exploratory approach to understanding the change process in its wider context, considering a broader range of factors and how they might be connected, and how different actors' perceptions and behaviours might be influencing this. Although still a simplification, it needed to provide sufficient relevant information to enable those responsible for managing any organised learning activity to manage its change and improvement.

Table 1 illustrates an example ToC model for an actual intervention. The approach used was a tabulated pipeline model (Funnell and Rogers 2011). There are no arrows on the diagram representing causation and direction of change. Rather the model seeks to incorporate relevant elements to guide a more exploratory and interpretative approach to understanding how different stakeholders conceptualise change, and should be revised as inquiry progresses and understanding develops. It is intended to take as a starting point questions about "how things are connected" rather than "does a cause b" (Patton 2012, p.250). Read from left to right, the model is still reasonably intuitive to interpret.

This illustrates a ToC used in a project intending to improve student learning by developing and introducing some new multimedia resources. This is a simplified version of the original, with some of the detail excluded. A decision taken about the modelling process in practice was that the models should be represented on a single 'view' if printed. In the case studies, this was either A4 or A3 poster, depending on the scale and complexity of the project. This was essentially a usability decision, 
where in this context "usability refers to the dimensions of evaluation design, within the power of evaluators to affect, which are likely to inhibit or enhance the chances of evaluation output being used" (Saunders 2012, p,433).

\section{Table 1: Example Theory of Change model for educational development project}

\begin{tabular}{|c|c|c|c|c|}
\hline $\begin{array}{l}\text { Contextual drivers } \\
\text { for change }\end{array}$ & $\begin{array}{l}\text { Resources/ } \\
\text { Enabling factors }\end{array}$ & $\begin{array}{l}\text { Activities/ } \\
\text { Processes }\end{array}$ & $\begin{array}{l}\text { Desired outcomes } \\
\text { (end of project) }\end{array}$ & $\begin{array}{l}\text { Anticipated longer-term } \\
\text { aspirations and impact }\end{array}$ \\
\hline $\begin{array}{l}\text { 1) Access to } \\
\text { recordings from } \\
\text { different eras of } \\
\text { history difficult for } \\
\text { students to access. } \\
\text { Limited opportunity to } \\
\text { formally introduce } \\
\text { them in the classroom. } \\
\text { 2) Increasing demand } \\
\text { from recording } \\
\text { industry for well } \\
\text { qualified graduates. } \\
\text { Graduates need to be } \\
\text { more competitive in } \\
\text { this job market. } \\
\text { 3) Music department } \\
\text { needs to retain } \\
\text { competitive advantage } \\
\text { as more universities } \\
\text { are introducing similar } \\
\text { content into the Music } \\
\text { curriculum. }\end{array}$ & $\begin{array}{l}\text { 4) Project team } \\
\text { develop a learning } \\
\text { resources with } \\
\text { following attributes:- } \\
\text { [detail excluded] } \\
\text { 6) Specialist support } \\
\text { supplied from central } \\
\text { university professional } \\
\text { services } \\
\text { [detail excluded] } \\
\text { 7) Teaching staff find } \\
\text { the learning resource } \\
\text { easy to use in their } \\
\text { teaching } \\
\text {-different locations } \\
\text {-updating content } \\
\text { 8) Students able to } \\
\text { access and use the } \\
\text { resource } \\
\text { independently }\end{array}$ & $\begin{array}{l}\text { 9) Teaching staff } \\
\text { motivate students to } \\
\text { critically engage with } \\
\text { resources to 'scaffold' } \\
\text { student learning for } \\
\text { the module. } \\
\text { 10) Students undertake } \\
\text { learning activities and } \\
\text { critically engage with } \\
\text { resources } \\
\text { [detail excluded] } \\
\text { 11) Students } \\
\text { independently use } \\
\text { resources prepare for } \\
\text { assessment } \\
\text { [detail excluded] } \\
\text { 12) Project team } \\
\text { disseminate their } \\
\text { approach and learning } \\
\text { from this in at least } \\
\text { two fora }\end{array}$ & $\begin{array}{l}\text { 13) Students positively } \\
\text { experience using the } \\
\text { learning resources to help } \\
\text { their learning } \\
\text { 14) Students develop } \\
\text { understanding of the } \\
\text { historical context of } \\
\text { recording and how this is } \\
\text { constructed through } \\
\text { multiple perspectives } \\
\text { 15) Students feel the } \\
\text { learning improves their } \\
\text { confidence in seeking } \\
\text { employment in the } \\
\text { recording industry } \\
\text { 16) Teaching staff have } \\
\text { better understanding of the } \\
\text { impact of resources on } \\
\text { student learning }\end{array}$ & $\begin{array}{l}\text { 17) Teaching staff extend } \\
\text { the approach to the rest of } \\
\text { the module (i.e. to cover } \\
\text { different eras) } \\
\text { 18) Students have } \\
\text { knowledge and skills to } \\
\text { help them secure a career } \\
\text { in the recording industry } \\
\text { 19) Good practice from } \\
\text { teaching approach adopted } \\
\text { elsewhere in Music } \\
\text { Department } \\
\text { 20) Music course retains } \\
\text { competitive advantage in } \\
\text { relation to other similar } \\
\text { courses taught at UK } \\
\text { Universities }\end{array}$ \\
\hline
\end{tabular}

The model is a user-defined scope or boundary for what Beer (1985) termed the 'system-in-focus'. This level of organised activity is nested in and contributes to a wider context of organised activity and is made up of 'sub-systems' working together to produce the emergent outcomes of the 'systemin-focus'. It provides a means of exploring with stakeholders the dimensions of the activity that they perceive relevant in guiding the inquiry towards answering their questions.

The left hand column reflects issues perceived to be affecting the current stability of the organised learning activity in its wider context. This provides the rationale for change, and should connect with the long term desired outcomes and impact represented in the extreme right hand column. (Due to space constraints, medium and long-term outcomes have been merged into a single column in this example). These together should describe how the relationship with the wider environment is anticipated to change through the activity undertaken, i.e. its purpose. This may represent connection with relevant higher level activity/strategy/context. What is relevant in defining 'purpose' may be perceived differently by different stakeholders, The model is only intended to guide inquiry into different stakeholder perceptions about 'success' and how it is achieved. Desired outcomes are those measures of success defined by the decision makers for the intervention, and thought to be more closely within their control through the activity they are responsible for organising. This may be helped or hindered by the extent to which they involve and communicate with other stakeholders to 
inform their understanding and commitment to their roles in influencing outcomes. Again, this is something the inquiry needs to explore. The activities and processes are those core activities anticipated to achieve the outcomes. Systems thinking guides decision makers to consider the range of stakeholder groups and what 'good' outcomes might look like for each. In the case of organised learning activity, pedagogical theory (e.g. Biggs and Tang 2011) encourages learning to be studentcentred, i.e. the primary client/beneficiary ought to be the learners whose learning is improved in some way. Other intended beneficiaries might be teachers, for example through improved workload or morale. The resources and enabling factors represent those preconditions highlighted as being most relevant in supporting the core activities. This is likely to be where some of the core project interventions may sit in the model.

This ToC model is a representation of a strategy in practice from the perspective of those constructing it. This is NOT the same as pedagogical theory (e.g. that of Kolb's (1984) theory about experiential learning), although this might form part of rationale for the strategy adopted. Indeed James (2011) review of practice found that those approaches found more helpful were when they were informed by wider relevant learning from outside the project or programme (research and practice). This is also where the facilitator can add value in critically questioning the pedagogical assumptions underpinning the intervention, and in bringing to the team their experience and knowledge of the process and success from previous interventions. Learning from the evaluation may also contribute to wider theory (Patton 2012).

\section{Deciding stakeholders to involve in modelling the Theory of Change}

The model represents perspectives involved in the process of developing it. As the critics have highlighted, one of the initial difficulties with participative approaches is in deciding who should be involved in this process, how, and who decides this. In the case studies, the primary purpose of the evaluation was to try and develop and engage project leaders in undertaking more rigorous action research into how changes in their teaching practice were supporting student learning i.e. the evaluation needed to be primarily designed to answer their questions, to inform their decisions and actions, and those of their teams. This fits with Patton's (1986) pragmatic notion of utilisation-focused evaluation, whereby the primary users are considered as those decision makers with a commitment to using the findings from the inquiry. Who else to involve also becomes their decision, and an issue for critical reflection about how the inquiry design influenced how the inquiry worked, what was found out and how this influenced improvement.

\section{Developing the initial Theory of Change model with stakeholders}

There is no prescribed method for facilitators to engage stakeholders in developing the conceptual models. A variety of approaches are used in practice, including workshops, interviews, and document analysis. In the case studies the project leader's 'theory of change' was to some extent already 
embedded in their written bid documents. Prior to an initial meeting with project leaders, and to avoid requiring project leaders to repeat this initial thinking process, a draft $\mathrm{ToC}$ model was produced based on my interpretation of the intervention articulated in the bid documents. This was used in the first meeting with project leaders to frame discussion about the project intervention, the purpose of evaluation, and how evaluation might be conducted. The number of participants in these initial meetings, and the number of meetings, varied depending on the scale and complexity of the projects. For example, some projects were being led and implemented by single innovators, and so these meetings were one-one. One particularly complex case involved a team of several members of staff from different departments, with varying roles in the project and the teaching team. The named project leader was relied on to provide initial information on these contacts. These were initially met with individually and also invited to name others they believed formed part of the core team. Any new information was also checked with the project leader. I was subsequently invited to attend departmental meetings where the evaluation would be discussed. The ToC was revised in these meeting(s) as team members were able to add clarification where they felt their strategy had been misrepresented, or key relevant issues were missing.

There is no assumption that there will be agreement between stakeholders about the ToC. However, as Ulrich (2000) argues, methodology can strive for agreement about the sources of disagreement.

Discussing this separately with different stakeholders or stakeholder groups in the initial stages does provide them with the opportunity to highlight any areas where there may be differences in perspectives. These are included in the ToC, to draw attention to the need to explore how these differences are perceived by stakeholders on implementation. For example, in this same complex project, a new collaborative and interdisciplinary learning activity with associated e-learning resources was being embedded within a number of different taught modules which were components of different programmes. This was being introduced to help students develop relevant professional skills, including working in multidisciplinary teams. However, the assessment mark for this activity was weighted differently in each of the overall module assessment marks. Some of the staff in the team highlighted that they felt this, and the variation in proximity to other assessment commitments, would affect the activity, although it was not exactly known how prior to the implementation. This became an issue recorded on the $\mathrm{ToC}$, guiding relevant data collection, so the team could reflect on how this worked in practice.

Whilst there is no prescribed approach to conducting the ToC development dialogue with project leaders and teams, the starting point is typically the overarching purpose of their project and rationale for this (drivers) that form the outer two columns of the model and the connection with the wider context. This involves consideration of key stakeholders and the intended benefits for these stakeholders. This is followed with considering outcomes expected within the defined period of the project (again in relation to different stakeholders), and those interim between the end of the project 
and the longer term impact. Whilst the end of the project was in most cases well defined by the project bid and the conditions of funding, this is not defined for the medium to long term outcomes. Project leaders were encouraged to articulate anticipated timescales for these to help them think about planning their cycles of evaluation, reflection and improvement. Discussion then proceeded to the process envisaged to achieve these outcomes, in terms of the activities (with actors), resources and contextual factors (both enablers and constraints). Even though the model is expressed in terms of those factors anticipated to have a positive influence on change, constraints do need to be considered so that project leaders can plan strategies for managing potential negative influences.

\section{Use of Theories of Change model}

The ToC model provides a shared framework for what is meant by 'improvement' at a particular point in time. The assumption is that improvement relies on iterative learning cycles involving stages of planning, implementing and evaluating organised activity. The ToC model provides a heuristic device guiding the direction of change. A simple illustration of the concept of heuristic is given by Beer (1981). Walkers attempting to reach the unseen peak of a hill with no specified route would use a general guide for action (heuristic) of 'keep going up'. Progress is determined by inquiry that generates information (feedback) to compare specific courses of action with the heuristic guide (e.g. take a step in each direction to determine which is higher) and inform decisions about the next step. As the strategy progresses and improvements made, what constitutes intended short, medium and long term outcomes will change.

In the educational development case studies, the ToC models were used to work collaboratively with project leaders in designing evaluation. For this purpose ToC provides a framework for deciding data/ information needed for insight into how and why the strategy may be working (or not) for different stakeholders. An initial consideration was what relevant data/information may be routinely available as a consequence of existing operational processes (e.g. e-learning tracking data, attendance records, assessment data....), and what further relevant data is needed and could be feasibly generated making use of the evaluation resource provided for the project. The meaning of data/information about a particular instance of improvement can be interpreted by reference to the ToC.

Many of the cases involved developing online interactive resources that were embedded in the virtual learning environment to support students' learning in some way. One example involved resource to enable students to observe borehole drilling techniques impossible to access in practice. Another involved the development of audio resources and quizzes to support tuition and allow speech therapy students to practice diagnosing language processing difficulties of patients. VLE tracking data provided some indication of the relative use of these new resources, and quiz responses provided some indication of what students could understand and apply. However, understanding the reasons for patterns in this data and the role the technology plays in supporting student learning could only be 
explored through dialogue with them. Student focus groups were used to gain insight into the diversity of student perspective. In these group situations, initial questions were kept open to encourage students to talk about the connections they were making between their learning experience and learning, with more specific probing or follow-up questions to learn more about intervention issues specifically identified by the project leaders/teams, or newly emerging in the discussion. Anonymous questionnaire feedback was used to gain some measure of students' perspectives in the whole implementation group. In cases where student availability permitted, it was useful to distribute these so that responses could be analysed in advance of focus groups, to help identify any particular issues for more in-depth exploration in the focus groups. However, in practice this was not often possible when student feedback was being collected at the end of an academic year after an implementation cycle. There was then often only a short window of student availability in which to gather student feedback.

This feedback was subsequently discussed with the project leaders/teams in a post-implementation reflective discussions, in which they would compare the student experiences and perspectives with their own, and consider alongside any other data available (e.g. VLE tracking data). Whether these post-implementation discussions are conducted with individuals, pairs or teams of staff is also something to which the facilitator needs to be contextually responsive.

\section{Timing of learning cycles}

ToC has been found useful in supporting ongoing reflection and learning (rather than one-off workshops) (James 2011), but maintaining this has been argued to be particularly challenging (Gareis 2010). Those responsible for change need to plan ahead appropriate intervals for this reflection and learning that are meaningful and feasible in relation to their own decisions and actions.

In figure 3 , these intervals of $T_{0}, T_{1}, T_{n}$ are not necessarily the same points of time at which the short, medium and long-term outcomes are anticipated to be achieved.

\section{Figure 3: Intervals for organised ToC evaluation and reflection}

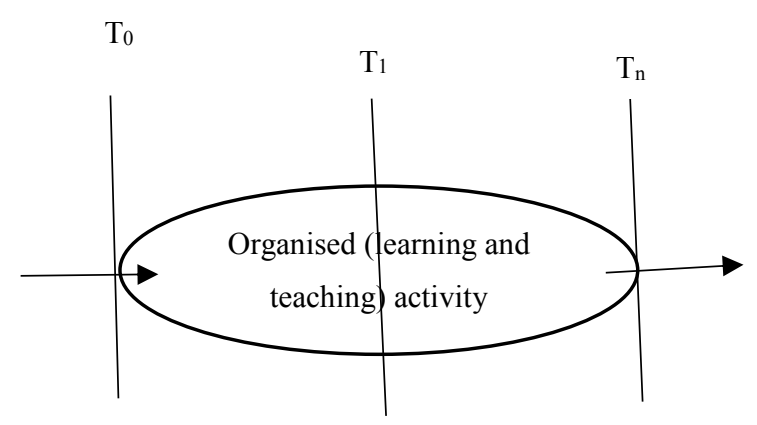

In the context of learning and teaching in higher education, the academic year cycle provides logical interval for review of a module, but there may be opportunity for partial review to inform some minor 
adjustments during the year. These cycles may be different depending on the level of organisation and scale of change and resource available, but as with other elements of the inquiry, this decision also needs to be reviewed for its value in practice.

\section{Critical reflection on application of the approach}

As well as facilitating evaluation in each project, I was also engaged in action research to improve the $\mathrm{ToC}$ approach in practice through the experience of applying this in multiple cases. Inquiry into the relationship between an evaluation and its relationship with the 'improvement' situation is referred to as second-order inquiry (e.g. Trevitt 2005, Martí and Villasante 2009), and it is this that is argued to bring rigour and improve the quality of action research for organisational learning (Argyris and Schön 1996). Systems thinking has also been argued to be a useful organising framework, not only for the first-order inquiry (directed at the situation of interest), but also for the second-order inquiry (Checkland and Holwell 1998, Midgley 2000, Hart and Pacaur-Caceres 2014). Figure 3 represents this relationship.

Figure 4: Relationship between first- and second-order inquiry in educational development

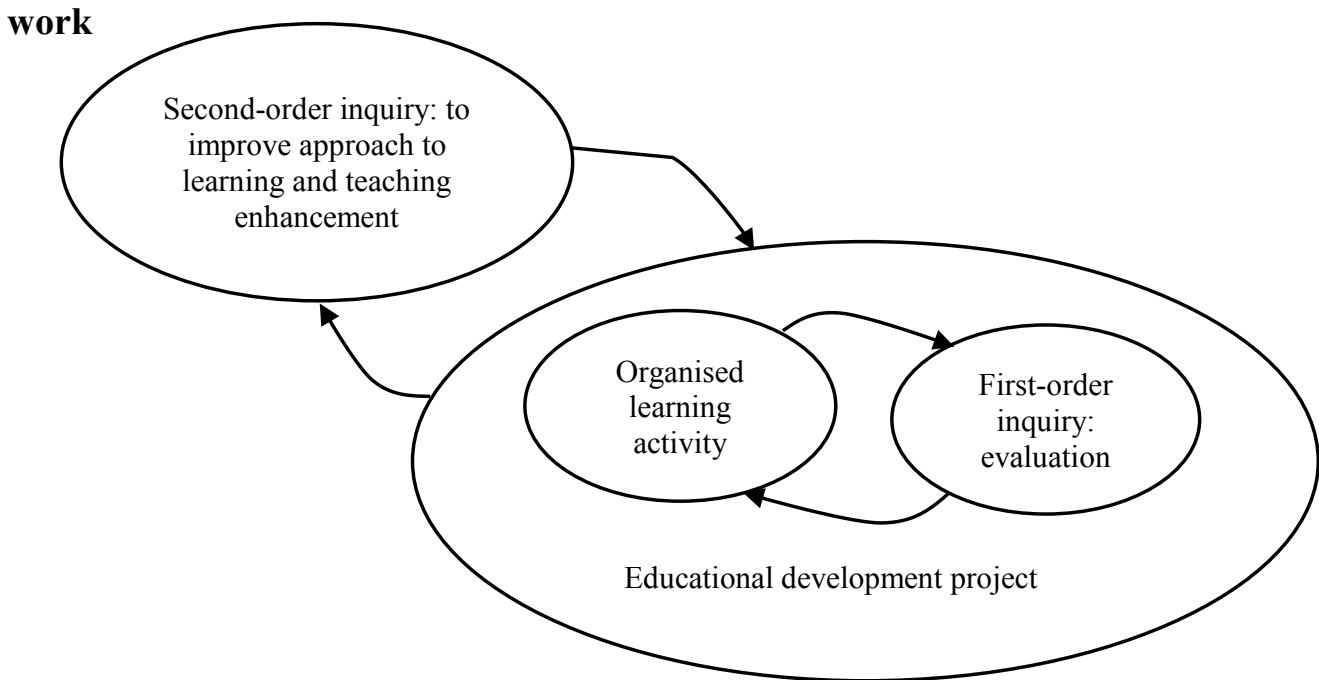

The following summarises some of my own assumptions, providing a 'boundary of relevance' guiding my action research into the ToC approach in these multiple case studies.

Purpose (of ToC approach): is assumed to be the generation of insight into how/why a particular learning and teaching strategy is working in context, to inform decisions about its improvement and contribute to understanding about good teaching practice. In addition, the approach is intended to support the development of practitioners capable and more engaged in rigorous action research into their learning and teaching strategies. 
Measures of performance: A key indicator of 'success' was assumed to be that the approach would be found to be usable and engaging for stakeholders, yielding relevant insight actually used in decision making about change in a process of continuous learning and teaching enhancement.

Client: For the evaluation, this was assumed to be the project leaders making enhancement decisions and interventions in the case studies. Others were institutional managers funding the initiative and with an interest in the more widely transferable learning from the projects.

Component activities: It was assumed that a facilitator would work collaboratively with project leaders in designing, implementing, reporting and disseminating the ToC evaluations.

Decision maker: Managers responsible for funding enhancement projects decided that ToC should be used as widely as possible in these projects. This expectation was communicated in successful bid notifications.

Designer: This could be conceptualised as a team of educational advisors with specialist knowledge in evaluation, advising on interpretation of generic ToC approach and its application in context, and gathering experience/intelligence about how the approach is working in practice to inform improvement in the approach. They are responsible for reporting this intelligence to the decision maker.

A key question guiding my critical reflection was therefore whether project leader's had perceived information generated by the evaluation relevant for informing their own improvement decisions (as client to the evaluation). Their typical comments were that it did indeed "focus on sensible issues" and resulted in "a huge amount of very useful detail". Another stated it helped to bring to his attention issues and make connections that he had not been sensitive to because of his close involvement in the project.

As an example, one project leader introduced a new approach to studying English texts, involving students producing multimedia presentations of their analysis and interpretation of literature. The assumption underpinning the project leader's 'theory of change' was that this would be a more engaging and creative way for students to demonstrate their understanding of the literature, and it would help them to reflect on the role new technologies play in communication. It would enable them to further develop their ICT skills (helping them to be more competitive in meeting demands of potential employers). Students were given the choice of whether to work individually or in pairs to create their assessed multimedia presentation. In the focus groups, those working in pairs stated that they felt this collaboration had really helped their learning. Those working individually stated that at the time they had not felt disadvantaged, but they had potentially missed out on some of the benefits of collaborating. Their choices had been made because they either did not know other students well enough to feel comfortable working with them, or they had a strong idea they wanted to pursue and 
could not find anyone with similar interests. They stated more opportunity should be created at the beginning of the module to explore and forge collaborative relationships. In reflecting on the impact of this decision on the implementation and student learning, the project leader stated he had not previously considered the conditions that would enable this choice and would do so in future implementations. This is a finding that would not have emerged without the qualitative dialogue about the elements of the learning process students particularly valued and felt helped them.

In the project involving students from different courses and departments working in multidisciplinary teams, the core 'theory of change' for the intervention was that working in multidisciplinary teams on the architectural and landscape designs for a real urban development site would simulate experience relevant to their future employment (Hart et al. 2009b). Student feedback from questionnaires and focus groups indicated that they found the group dynamics challenging, as the engagement of team members was variable, influenced by a range of factors such as variability in their timetables and workloads. From the perspective of academic staff, this experience was highly relevant to students' future employment and an important dimension of the learning. Many of the students also acknowledged this. This resulted in the team deciding they would need to do more to manage students' expectations and help them to develop strategies for dealing with this, and give credit for critically reflecting on this experience and learning in the assessment.

This latter provides an example of how I was able to observe use of the evaluation in informing decisions for change. There was limited opportunity to gather insight into the translation of decisions into enhancement action. Within the timescale of my own action research I was only able to revisit one case to support the team in a second iteration of evaluation. I participated in team meetings where the team reflected on their experiences and student feedback, including changes made as a consequences of the previous cycle of evaluation. For all of the case studies that I was involved in progress was made with sharing good practice. Evaluations were used to create written case studies posted on the university intranet. In some cases they were used in project leaders' conference presentations. It was difficult to assess whether the ToC approach had engaged and helped project leaders in adopting a more continuous, systematic and rigorous approach to their own action research. From my own experience, producing an initial draft ToC from existing documentation seemed to be a key factor in relationship management with project leaders. I found one of the advantages to be time saving. Opening dialogue with a contextual illustration a ToC model helped in explaining its role in guiding evaluation/reflection. It helped me to develop the trust of project leaders as I had already invested time in trying to develop a reasonable understanding of their plans, and was able to use this to talk about how the $\mathrm{ToC}$ would guide inquiry to focus on issues relevant to them. This trust was indicated on a number of occasions where I was invited to attend classes to observe learning activity, received project leader support in encouraging student feedback, and was invited to participate in 
team meetings, conference presentations and the writing of a journal article (Hart et al. 2009b). I also found that project leaders were willing to accept the advice about the approach to data generation, presumably because they could more transparently see the connection with how this would inform their own decisions. Another advantage I found from the perspective of facilitator, was that having the $\mathrm{ToC}$ framework helped me to quickly make sense of a project when I needed to cover for colleagues. The use of systems thinking helped me to consider where there may be gaps in the project leader's thinking or explicit articulation of this thinking, and to help make this explicit e.g. in considering the rationale for change in terms of its connection with the wider environment or higher levels of organisation/strategy.

A key decision to reflect on in the applications of ToC was that in most cases students were not involved as full participants in the approach, although some of the project plans were influenced by earlier student feedback, and evaluation of projects always used student feedback. Existing literature discusses that involving a diverse range of stakeholders that take ownership of the process is helpful (James 2010), and there has been growing emphasis on engaging students as partners in educational enhancement initiatives (e.g. Levy 2012, Trowler et al. 2014). Others have questioned the aspirations of participative approaches, finding that not all stakeholders are willing or able to participate (Ulrich 2000), or there is not practically the time or resource to achieve the relationships envisaged by ToC (Sullivan et al. 2002, Hart et al. 2009a). In most of the educational development projects the specific group of students that would be involved in the implementation would not have been known in sufficient time before its implementation to have been involved in the planning process, and would have insufficient knowledge and experience of pedagogy and curriculum design. However, the project leaders who had observed issues related to the different assessment weightings, and choices with relation to collaboration in assessment, stated that some earlier student input would have been helpful in anticipating and planning strategies for dealing with them. There was evidence of helpful input from other participants, for example in one case a visiting professor still practicing in the relevant employment sector was able to participate in meetings in which the evaluation plans and findings were discussed, to provide a different perspective on interpreting the findings and in helping with decision-making about future plans. In this same project, practitioners were also involved in the assessment of students' poster presentations, so were available as data sources about the relevancy of the learning to practice.

At the time I was involved in this action research, the longer term aspirations of introducing the ToC approach were that it would become embedded as an approach to enhancement, as more staff engaged with it, had positive experiences of using it, and it benefited their own practice. As longer term aspirations we did not yet have sufficient evidence of this. Project leaders did not seem to have any difficulty in understanding the purpose and process of developing and using the ToC. One in particular highlighted that it was useful in structuring the facilitator's impartial, critical questioning to 
stimulate the project team's relevant critical reflection on their decisions about their teaching. The positive experiences of engaging with staff in using the approach would suggest it was a step in the right direction when compared to approaches previously used. However, conducting more continuous, systematic and rigorous action research requires more resource than the traditional 'reflective practitioner' model. A consideration for how this worked for project leaders was that resource to conduct the evaluation was specifically provided for the project, and without adequate resource/time to engage in this activity it is unlikely that teaching practitioners would routinely build this into their everyday practice (Bamber and Anderson 2012).

With respect to improving the connection between different levels of change, systems thinking does improve consideration of this connection, however in these cases this relied heavily on the facilitator knowledge of systems theory and practice and how this can be applied practically in the ToC approach, to help project leaders to include these in their ToC. The other benefits this facilitation brings is in being able to bring to a particular project their learning and experience from other projects relevant either to the implementation situation or the evaluation of it. In this sense they may become 'boundary spanners' (Wenger et al. 2002) providing connections across different organisational learning communities. In this learning and teaching context this helped connection between different departments, and in some cases, institutions.

\section{Summary}

The approach outlined in this chapter presents a personal interpretation of a ToC approach with the intention of supporting evaluation in a specific context of learning and teaching enhancement in a university. This has only been provided in sufficient detail to help readers understand the particular approach to implementation in this context. The critical reflection provided is not presented as 'proof' of effectiveness or good practice, but intended only to provide insight into what was found useful and learned from the applications in this context. This may be helpful for others, to help assess the usefulness and transferability to other situations of interest, particular issues for consideration, and the further adaptation or improvement that may be needed. In other words, it captures learning from a particular perspective, in a specific context, at a specific time, that represents a point on a continuum of learning about the application of the approach in practice.

\section{References}

Ackoff, Russell L. 1981. Creating the corporate future. New York: John Wiley and Sons.

Archibald, Thomas, Guy Sharrock, Jane Buckley, and Natalie Cook. 2016. “Assumptions, conjectures and other miracles: The application of evaluative thinking to theory of change models in community 
development." Evaluation and Program Planning 59:119-127.

DOI:10.1016/j.evalprogplan.2016.05.015.

Argyris, Chris, and Donald A. Schön. 1996. Organizational learning II: Theory, Method and practice. Reading, Ma: Addison-Wesley.

Association for Project Management. 2017. "Body of Knowledge: Glossary." https://www.apm.org.uk/membership/?gclid=CJ6c65jL8dMCFaK37Qodg4EJ-A. Accessed on 15 May 2017.

Bamber, Veronica, and Sally Anderson. 2012. "Evaluating learning and teaching: institutional needs and individual practices." International Journal for Academic Development 17 (1):5-18. DOI: $10.1080 / 1360144 X .2011 .586459$

Barefoot, Helen, Martin Oliver, and Harvey Mellar. 2016. "Informed Choice? How the United Kingdom's key information set fails to represent pedagogy to potential students." Quality in Higher Education 22 (1):3-19. DOI: 10.1080/13538322.2016.1153899

Barnes, Marian, Elizabeth Matka, and Helen Sullivan. 2003. "Evidence, Understanding and Complexity: Evaluation in non-linear systems.” Evaluation 9 (3):265-284.

Beer, Stafford. 1981. The brain of the firm. $2^{\text {nd }}$ Edition. Chichester: John Wiley Ltd.

Beer, Stafford. 1985. Diagnosing the system for organizations. Chichester: John Wiley and Sons Ltd. Biggs, John. 2001. "The reflective institution: Assuring and enhancing the quality of teaching and learning." Higher Education 41 (3):221-238. DOI: 10.1023/A:1004181331049.

Biggs, John B., and Catherine S. Tang. 2011. Teaching for quality learning at university: what the student does. $4^{\text {th }}$ Edition. Open University Press: Maidenhead.

Breuer, Erica, Lucy Lee, Mary De Silva, and Crick Lund. 2016. "Using theory of change to design and evaluate public health interventions: a systematic review." Implementation Science 11 (1): 63-79. DOI: $10.1186 / \mathrm{s} 13012-016-0422-6$.

Checkland, Peter. 1981. Systems thinking, systems practice. Chichester: John Wiley and Sons Ltd. 
Checkland, Peter, and Sue Holwell. 1998. "Action Research: Its nature and validity.” Systemic Practice and Action Research 11 (1): 9-21. DOI: 10.1023/A:1022908820784.

Churchman, C. West. 1971. The design of inquiring systems. New York: Basic Books.

Connell, James P., and Anne C. Kubisch. 1998. “Applying a Theory of Change Approach.” In New approaches to evaluating community initiatives, Volume 2: Theory, measurement, and analysis, edited by Karen Fulbright Anderson, Anne C. Kubisch, and James P. Connell, 15-44. Washington DC: The Aspen Institute.

Crawford, Lynn, and Anat H. Nahmias. 2010. “Competencies for managing change.” International Journal of Project Management 28:4015-412. DOI: 10.1016/j.ijproman.2010.01.015

Davies, Rick. 2004. "Scale, complexity and the representation of Theories of Change." Evaluation 10 (1):101-121. DOI:10.1177/1356389004043124.

Davis, Brent, and Dennis Sumara. 2005. "Complexity science and Educational Action Research: towards a pragmatics of transformation." Educational Action Research 13 (3): 453-464.

DBIS (Department of Business, Innovation and Skills). 2016. Success as a Knowledge Economy: Teaching Excellence, Social Mobility and Student Choice. London: The Stationery Office. https://www.gov.uk/government/uploads/system/uploads/attachment_data/file/523396/bis-16-265success-as-a-knowledge-economy.pdf . Accessed on July 32017.

Fetterman, David M. 1994. “Empowerment evaluation.” Evaluation Practice 15 (1): 1 -15. DOI: 10.1016/0886-1633(94)90055-8.

Franco, Alberto L., and Gilberto Montibeller. 2010. "Facilitated modelling in operational research." European Journal of Operational Research 205 (3):489-500.

Funnell Sue C., and Patricia J. Rogers. 2011. Purposeful Program Evaluation: Effective use of theories of change and logic models. San Francisco:Jossey-Bass.

Gareis, Roland. 2010. “Changes of organizations by projects.” International Journal of Project Management 28: 314-327. DOI: 10.1016/j.jpproman.2010.01.002. 
Gates, Emily F. 2017. "Learning from seasoned evaluators: Implications of systems approaches for evaluation practice.” Evaluation 23 (2) :152-171. DOI: 10.1016/j.ijproman.2010.01.002.

Gibbs, Graham. 2010. Dimensions of Quality. York: Higher Education Academy.

Greenbank, Paul. 2007. "Utilising collaborative forms of educational action research: some reflections." Journal of Further and Higher Education 31 (2):97-108. DOI:

$10.1080 / 03098770701267531$

Gunn, Vicky, and Anna Fisk. 2013. Considering teaching excellence in higher education: 2007-2013. York: Higher Education Academy.

https://www.heacademy.ac.uk/system/files/resources/telr_final_acknowledgements.pdf. Accessed on July 52017.

Hart, Diane, Gabi Diercks-O’Brien, and Adrian Powell. 2009a. "Exploring stakeholder engagement in impact evaluation planning in educational development work." Evaluation 15 (3): 285-306.

Hart, Diane, John Hughes, David Lerner, Roger Lewis, Ian Ward, Aiden While, Ryan Wilson, and Lorna Walker. 2009b. “An Interdisciplinary Approach to Enhancing Sustainable Development Teaching in the Higher Education Built Environment Curriculum: Learning From a Curriculum Development Project at the University of Sheffield." Reflecting Education 5(1): 31-50. http://www.reflectingeducation.net/index.php/reflecting/article/view/74 . Accessed on July 52017. Hart, Diane, and Alberto Paucar-Caceres. 2014. "Using Critical Systems Heuristics to Guide SecondOrder Critique of Systemic Practice: Exploring the Environmental Impact of Mining Operations in Southern Peru." Systems Research and Behavioral Science. 31(2):197-214. DOI: 10.1002/sres.2195. Hart, Diane, and Alberto Paucar-Caceres. 2017. “A utilisation focussed and viable systems approach for evaluating technology supported learning." European Journal of Operational Research 259 (2):626-641. DOI: 10.1016/j.ejor.2016.10.056.

Harvey, Lee, and James Williams. 2010a. "Fifteen years of quality in higher education." Quality in Higher Education 16 (1):3-36. DOI: 10.1080/13538321003679457. 
Harvey, Lee, and James Williams. 2010b. "Fifteen years of quality in higher education (Part 2)."

Quality in Higher Education 16 (2): 81-113. DOI: 10.1080/13538322.2010.485722

Higher Education and Research Act. 2017.

http://www.legislation.gov.uk/ukpga/2017/29/contents/enacted/data.htm. Accessed on 14 July 2017.

Hopkins, Matt, and Julia Wickson. 2013. “Targeting prolific and other priority offenders and promoting pathways to desistance: Some reflections on the PPO programme using a theory of change framework." Criminology and Criminal Justice 13 (5): 594-614. DOI: 10.1177/1748895812462595.

Houston, Don. 2008a. "Rethinking quality and improvement in higher education." Quality Assurance in Higher Education 16 (1):61-79. DOI: 10.1108/09684880810848413.

Houston, Don. 2008b. "Systemic intervention in a university department: Reflections on arrested action research." Systems Practice and Action Research 21:133-152. DOI: 10.1007/s11213-007-9087-

Z

Hummelbrunner, Richard. 2011. "Systems thinking and evaluation." Evaluation 17 (4):395-403.

DOI: $10.1177 / 1356389011421935$

Imam, Iraj, Amy LaGoy, and Bob Williams. 2007. "Introduction". In Systems concepts in evaluation: An expert anthology, edited by Bob Williams B and Iraj Imam, 3-10. Point Reyes, Ca: Edge Press. Jackson, Michael C. 2003. Systems thinking: Creative Holism for managers. Chichester: Wiley. Jacobs, Gaby. 2016. "'A guided walk in the woods': boundary crossing in a collaborative action research project." Educational Action Research. DOI: 10.1080/09650792.2016.1203344 James, Cathy. 2011. Theory of change review: A report commissioned by Comic Relief. http://www.actknowledge.org/resources/documents/James_ToC.pdf. Accessed May 152017. Kember David. 2002. "Long-term outcomes of educational action research projects." Educational Action Research 10 (1):83-103. 
Kirkwood, Adrian, and Linda Price. 2014. "Technology-enhanced learning and teaching in higher education: what is 'enhanced' and how do we know? A critical literature review." Learning, Media and Technology 39(1): 6-36. DOI: 10.1080/17439884.2013.770404.

Kolb, David A. 1984. Experiential learning: Experience as the source of learning and development. New Jersey: Prentice Hall Inc.

Levy, Philippa. 2012. "Developing Inquiry-guided Learning in a Research University in the United Kingdom.” New Directions for Teaching and Learning, 129: 15-26.

Mackenzie, Mhairi, and Avril Blamey. 2005. "The practice and the theory: Lessons from the application of a Theories of Change approach.” Evaluation 11 (2):151-168. DOI: :

$10.1177 / 1356389005055538$.

Marks-Maran, Diane. 2015. "Educational research methods for researching innovations in teaching, learning and assessment: The nursing lecturer as researcher." Nurse Education in Practice 15 (6): 72 479. DOI: 10.1016/j.nepr.2015.01.001.

Martí, Joel, and Tomás R. Villasante. 2009. "Quality in action research: Reflections for second-order inquiry." Systems Practice and Action Research 22:383-396. DOI: 10.1007/s11213-009-9136-x.

Mason, Paul, and Marian Barnes. 2007. "Constructing Theories of Change: Methods and sources." Evaluation 13 (2):151-170. DOI: 10.1177/1356389007075221.

Mayne, John, and Nancy Johnson. 2015. "Using theories of change in the CGIAR Research Program on Agriculture for Nutrition and Health." Evaluation 21 (4): 407-428. DOI:

$10.1177 / 1356389015605198$.

Midgley, Gerald. 2000. Systemic Intervention: Philosophy, methodology and practice. New York: Kluwer Academic.

Patton, Michael Q. 1986. Utilization-focussed evaluation. Newbury Park, Ca: Sage Publications, Inc. Patton, Michael Q. 1994. Developmental Evaluation, Evaluation Practice 15 (3): 311-319 
Patton, Michael Q. 2012. Essentials of Utilization-Focused Evaluation. Thousand Oaks: Sage Publications, Inc.

Pawson, Ray, and Nick Tilley. 1997. Realistic evaluation. London: Sage Publications Ltd.

Quality Assurance Agency. 2017. The UK Quality Code for Higher Education: General Introduction. http://www.qaa.ac.uk/assuring-standards-and-quality/the-quality-code. Accessed May 162017.

Radford, Mike. 2006. "Researching classrooms: complexity and chaos." British Educational Research Journal 32 (2):177-190Singer

Radford, Mike. 2008. "Prediction, control, and the challenge to complexity." Oxford Review of Education 34 (5):505-520. DOI: 10.1080/03054980701772636.

Richards, Deborah, Sonia Saddiqui, Fiona White, Nicholas McGuigan, Judi Homewood. 2016. “A theory of change for student-led academic integrity." Quality in Higher Education 22 (3): 242-259. DOI: $10.1080 / 13538322.2016 .1265849$.

Saunders, Murray. 2012. "The use and usability of evaluation outputs: A social practice approach." Evaluation 18 (4): 421-436. DOI: 10.1177/1356389012459113.

Saunders, Murray, Bernadette Charlier, and Joel Bonamy. 2005. "Using evaluation to create 'provisional stabilities': Bridging innovation in higher education change processes." Evaluation 11 (1):37-54. DOI: $10.1177 / 1356389005053188$.

Schön, Donald A. 1983. The reflective practitioner: how professionals think in action. New York: Basic Books Inc.

Stefani, Lorraine. 2003. "What is staff and educational development?” In A Guide to Staff and Educational Development edited by Peter Khan and Davide Baume, 9-23. London:Kogan Page.

Sullivan, Helen, Marian Barnes, and Elizabeth Matka. 2002. "Building collaborative capacity through 'Theories of Change': Early lessons from the evaluation of Health Action Zones in England." Evaluation 8 (2): 205-226. 
Sullivan, Helen, and Murray Stewart. 2006. "Who owns the Theory of Change?" Evaluation 12 (2):179-199. DOI: $10.1177 / 1356389006066971$

Thornton, P.K., T. Schuetz, W. Förch, L. Cramer, D. Abreu, S. Vermeulen, and B.M. Campbell. 2017. "Responding to global change: A theory of change approach to making agricultural research for development outcome-based.” Agricultural Systems 152:145-153. DOI. 10.1016/j.agsy.2017.01.005. Trevitt, Chris. 2005. Universities learning to learn? Inventing flexible (e) learning through first- and second- order action research. Educational Action Research 13 (1): 57-83. DOI:

$10.1080 / 09650790500200277$.

Trowler Paul, Joelle Fanghanel, and Terry Wareham. 2005. "Freeing the chi of change: the Higher Education Academy and enhancing teaching and learning in higher education. " Studies in Higher Education 30 (4):427-444. DOI: 10.1080/03075070500160111

Trowler, Paul, Paul Ashwin, and Murray Saunders. 2014. The Role of HEFCE in teaching and learning enhancement: a review of evaluative evidence, York: Higher Education Academy. https://www.heacademy.ac.uk/system/files/downloads/The_role_of_HEFCE_in_TL_Enhancement_fi nal report.pdf. Accessed on June 302017.

UKCES. 2014. The Labour Market Story: Skills for the Future. Briefing Paper. London: UK Commission for Employment and Skills. https://www.gov.uk/government/uploads/system/uploads/attachment_data/file/344441/The_Labour_ Market_Story-_Skills_for_the_Future.pdf. Accessed July 32017.

Ulrich, Werner. 1987. "Critical heuristics of social systems design.” European Journal of Operational Research 31: 276 - 283. DOI: 10.1016/0377-2217(87)90036-1

Ulrich, Werner. 2000. "Reflective practice in the civil society: the contribution of critically systemic thinking." Reflective Practice 1 (2):248-268. DOI: 10.1080/713693151.

Vince, Russ. 2002. “Organizing reflection.” Management Learning 33 (1):65-78. DOI: $10.1177 / 1350507602331003$. 
Virtanen, Petri, and Petri Uusikylä. 2004. "Exploring the missing links between cause and effect: A conceptual framework for understanding micro-macro conversions in programme evaluation." Evaluation 10 (1):77-91. DOI: 10.1177/1356389004043136.

Wenger, Etienne, Richard A. McDermott, and William M. Snyder. 2002. Cultivating communities of practice. Boston: Harvard Business School Press. 